\title{
O DESAFIO DA TARTARUGA HUMEANA
}

\author{
Elson L. A. Pimentel ${ }^{1}$
}

RESUMO Descrevo neste artigo os argumentos que Blackburn colocou na disputa entre Aquiles e a tartaruga a respeito das razões que motivam as ações humanas. Por subscreverem posições nitidamente humeanas, as idéias da tartaruga não se enquadram perfeitamente em nenhuma das correntes polarizadoras das opiniões contemporâneas a respeito do tema, mesmo sendo próximas às dos neo-humeanos. Com isso, o chamado "desafio humeano", que joga para o proponente de razoes categóricas o ônus de provar sua existência, fica agravado pelo retorno à posição original de Hume de que não há razões, sejam elas hipotéticas ou categóricas, que movem os homens, apenas as paixões.

Palavras-chave: razão prática, motivação, decisão, paixões

ABSTRACT I describe in this article the arguments that Blackburn put in dispute between Achilles and the turtle regarding the reasons that motivate human actions. For they sign sharply Humean positions, the ideas of the turtle are not framed perfectly in none of the polarizing currents of the contemporary philosophy regarding the theme, although close to neo-Humean pole. In this way, the so called "Humean challenge", that throws to the proponent of categorical reasons the onus to argue for their existence, become worsened by the return to the Hume original position that there are no reasons, be them hypothetical or categorical, that could move human being, just passions.

1 Mestrando em Filosofia - UFMG. Artigo recebido em setembro e aprovado em novembro.

KRITERION, Belo Horizonte, $\mathrm{n}^{0}$ 108, Dez/2003, p.290-300 


\section{Introdução}

No resumo de um debate no âmbito do internalismo sobre a possibilidade da existência de conexões conceituais entre razões normativas e motivação, Cullity e Gaut, em Ethics and Practical Reason, agrupam as diversas concepções existentes na filosofia contemporânea em três pólos: um neo-humeano, outro kantiano, e um terceiro aristotélico.

A visão tipicamente neo-humeana é que há razões apenas hipotéticas, que dependem das tendências motivacionais do agente. Em oposição, kantianos e aristotélicos acreditam em razões não-hipotéticas, ou categóricas, pois consideram que estamos submetidos, respectivamente, ou à natureza do agente racional livre ou à especificidade da natureza humana.

Para os aristotélicos, a razão prática tem o papel de reconhecer se uma ação é valiosa por si só, independentemente da escolha racional. Oposta a essa, há uma visão construtivista em que ação é valiosa quando ela for o objeto de escolha racional. Enquanto em Kant essa concepção é encontrada na forma pura, muitos humeanos compartilham a idéia de que o valor é fruto de uma reflexão racional.

Os três pólos endossam um universalismo das razões, mas a doutrina kantiana vai mais além, impondo um universalismo legislativo que governa a razão prática, ou, de outra forma, um imperativo categórico motiva a ação.

A posição neo-humeana tem alguns desvios significativos em relação ao pensamento de Hume: primeiro, as paixões, concebidas como sentimentos presentes em todas as motivações, são substituídas por desejos, os quais se pode ter num momento sem senti-los nesse momento; em segundo lugar, a razão, para Hume, é direcionada à verdade e não à ação, não havendo razões normativas, sejam elas hipotéticas ou categóricas.

Para Cullity e Gaut, a melhor justificativa para esse desvio não-cético nas suposições neo-humeanas talvez seja a visão do próprio Hume de que "os desejos últimos de um agente (...) não estão sujeitos à crítica da razão" ${ }^{2}$, abrindo caminho para uma concepção instrumental da razão prática, pela qual a razão busca os meios para realizar os fins dessa pessoa ${ }^{3}$.

B. Williams lançou aos que defendem as normas que geram razões categóricas o ônus de provar a sua existência, configurando o desafio humeano: "como pode haver razões categóricas, e especificamente, razões categóricas morais?" ". O caminho que escolhemos para desenvolver esse tema foi buscar

2 Cullity e Gaut, p. 8, n. 14. Citação de Hume, An Enquiry Concerning the Principles of Moral, pp. 162-3.

3 Ibidem, p. 8, n. 15: Ao se adicionar a consideração de que os desejos últimos de todos os agentes são autointeressados, produz-se a 'concepção econômica' da razão prática.

4 Ibidem, p. 10, n. 21. Citação de Bernard Williams, "Internal and External Reasons", in Moral Luck, pp. 101-13. 
compreender melhor a fundamentação desse desafio, tendo como objeto de pesquisa um texto de Simon Blackburn, Practical Tortoise Raising.

\section{O diálogo de Blackburn}

Num paradoxo conhecido desde a antiguidade, Zenão descreve uma corrida entre Aquiles e a tartaruga, em que, na largada, ele dava a ela uma certa distância de vantagem; no instante em que Aquiles atingia a posição da tartaruga, esta já havia avançado mais um pouco e, por mais que o processo se repetisse e a distância encurtasse, a tartaruga nunca era alcançada.

Há cerca de cem anos, Lewis Carroll (autor de Alice in Wonderland) publicou em Mind uma versão dessa história, What the Tortoise said to Achilles, onde, ao escutar um argumento de Aquiles, a tartaruga seguidamente questionava se não estaria faltando uma nova premissa que, introduzida, sempre adiava a conclusão.

Em 1995, na edição comemorativa dos 100 anos do artigo de Carroll, Mind publica uma nova versão do diálogo, Practical Tortoise Raising, de Simon Blackburn. Nesse texto, ele reforça o desafio humeano referido anteriormente, ao defender uma concepção de racionalidade segundo a qual a vontade não está sob o controle apenas de uma combinação de fatos e da razão, mas há sempre algo mais que independe desses fatores - as paixões.

\subsection{Um resumo do diálogo}

O diálogo entre Aquiles e a tartaruga se divide em cinco partes: o problema da motivação da ação; a contribuição que a teoria da escolha racional poderia dar; a possibilidade do imperativo categórico; a proposta do raciocínio meio-fins; e, finalmente, a solução das paixões.

Aquiles e a tartaruga discutem se, no seguinte argumento, partindo-se das premissas chega-se à conclusão:

- Eu prefiro comer alface a comer souvlaki.

- O momento da decisão é agora.

- Deixe-me escolher comer alface em vez de souvlaki! ${ }^{5}$

Ambos concordam que, para isso acontecer, a vontade tem que estar determinada e uma intenção formada, mas percebem que, mesmo se adicionassem razões do tipo:

5 Blackburn, 1995, p. 696. Souvlaki: prato feito com carne de cordeiro. 
$\checkmark$ Eu penso que é certo preferir alface a souvlaki.

$\checkmark$ Eu penso que é racional fazer o que eu penso que é certo.

$\checkmark$ Eu penso que é certo fazer o que eu penso que é racional.

$\checkmark$ Eu prefiro fazer o que eu penso que é certo e racional fazer. ${ }^{6}$

sempre faltaria algo para que a ação fosse motivada. Aquiles vai então em busca de ajuda nos livros da Teoria da Escolha Racional, segundo a qual uma pessoa atribui valores ('utilidades') às opções de um conjunto ordenado de suas preferências, que visam não só os próprios interesses, mas também os interesses de outros. As preferências dessa pessoa se revelam pelas escolhas que faz, quaisquer que sejam suas motivações.

Eles querem saber se é possível tirar dessa teoria alguma recomendação para a ação, em especial pelo estudo do dilema do prisioneiro ${ }^{7}$, um jogo cooperativo de soma não-nula, em que os dois jogadores podem, juntos, ganhar ou perder, conforme as opções fornecidas pela seguinte tabela de resultados (ao escolher, cada jogador não conhece a escolha do outro) ${ }^{8}$ :

\section{Dilema do prisioneiro ${ }^{9}$}

(o ganho de A está representado em primeiro lugar)

\begin{tabular}{c|c|c|c|}
\multicolumn{1}{c}{} & \multicolumn{2}{c}{ Jogador A } \\
\cline { 3 - 4 } Jogador B & Não cooperar & Cooperar \\
\cline { 2 - 4 } & Não cooperar & 1,1 & 0,3 \\
\cline { 2 - 4 } & Cooperar & 3,0 & 2,2 \\
\cline { 2 - 4 } & &
\end{tabular}

Ao conselho de um teórico para jogar a estratégia dominante - não cooperar - pois o resultado seria mais vantajoso, qualquer que seja a jogada do outro, a tartaruga reage: se não seguir o conselho, não estaria revelando uma preferência diferente, mostrando que os números da matriz estariam errados — enfim, negando o dilema do prisioneiro? ${ }^{10}$

6 Ibidem, pp. 696-7.

7 Em geral, o dilema do prisioneiro se caracteriza por uma tentação a não cooperar (valor 3) maior que a recompensa a cooperar (valor 2), ambos maiores que a punição pela não-cooperação (valor 1), e o prejuízo do otário (valor 0) que coopera sozinho e propicia o ganho do outro. Além disso, a recompensa deve ser maior que a média da tentação e do prejuízo do otário. O exemplo mais comum de dilema do prisioneiro na vida diária é o caso do 'carona', que se aproveita do esforço de outros e se nega a contribuir. Ver Poundstone, pp. 118-27.

8 Em Ruling Passions (p. 177), Blackburn sugere os seguintes nomes para as opções: Vitória (valor 3), Cooperação (valor 2), Guerra (valor 1) e Ruína (valor 0).

9 Blackburn, 1995, p. 701.

10 Não basta envolver dois agentes, haver duas opções e ter soma não-nula para ser um dilema do prisioneiro. Apesar de simples, essa estrutura $2 \times 2$ produz setenta e oito jogos distintos pela combinação dos valores relativos da matriz de resultados. Uma situação semelhante ao dilema do prisioneiro, e que às vezes é 
É isso que faz a diferença entre um jogo teórico e uma situação empíri$\mathrm{ca}^{11}$. Na teoria, é feita uma modelagem de regras e comportamentos que podem não refletir toda a diversidade de opções que os agentes vão encontrar na prática, e cujas preferências só vão ser reveladas ao agir. Assim, se a matriz teórica de resultados for conhecida com antecedência, é tautológico recomendar que se jogue a estratégia dominante (não cooperar), pois os agentes representados pelo modelo não têm realmente que fazer uma escolha: eles já sabem qual é o melhor resultado para si.

Uma situação empírica é melhor ilustrada pelo jogo a seguir:

Jogo da Chantagem

(o ganho de Adão está representado em primeiro lugar)

\begin{tabular}{|l|c|}
$\mathrm{t}_{1}$ & Adão \\
\hline Pomba & 1,2 \\
\hline Falcão & $\odot$ \\
\hline
\end{tabular}$\quad$\begin{tabular}{|l|l|}
$\mathrm{t}_{2}$ & Eva \\
\hline Pomba & 2,1 \\
\hline Falcão & 0,0 \\
\hline
\end{tabular}

Antes de começar o jogo, Eva comete uma indiscrição (indiscretion). Se Adão não fizer nada (pomba) ele terá uma unidade de utilidade, e Eva 2. Se ele chantagear Eva (falcão) e ela aceitar a chantagem (pomba), ele toma 1 unidade de Eva. Mas, se ela não se submeter (falcão), chutará tudo para cima, revelando-o como chantagista e a si mesma como indiscreta, deixando ambos na pior situação final, o 0,0 .

Na teoria de decisão ortodoxa, (...) uma Eva qualificada não jogará falcão na opção final, pois isso representaria uma perda. Um Adão qualificado sabe disso: ele jogará falcão e ela jogará pomba, realizando a chantagem com sucesso. (...)

[Na prática, Eva] precisa mostrar-se vingativa e orgulhosa, não inclinada a se submeter à chantagem, preferindo a própria ruína e a de Adão, a se sentir vítima. Se souber que vai enfrentar tal situação regularmente, deve cultivar publicamente uma boa imagem má, tal que sua ameaça de expor a ambos seja bastante crível. ${ }^{12}$

A conclusão é que nada na teoria dos jogos pode ser traduzido em conselhos, pois mesmo seguir a estratégia dominante mostra-se inútil na prática ${ }^{13}$. A

confundido com ele, é o jogo da coordenação, em que o prêmio maior é para cooperar, pois os interesses são os mesmos - como dois remadores num barco. Outro caso semelhante ao dilema do prisioneiro, e que também às vezes é confundido com ele, é o jogo do covarde (chicken), exemplificado por adolescentes que dirigem dois carros em alta velocidade, um de encontro ao outro, até que um deles, o covarde, desvie. Nesse caso, cada jogador quer fazer exatamente o oposto do que o outro fizer, e o pior resultado é a nãocooperação mútua. Ver Poundstone, pp. 197-99 e 215-20.

11 Blackburn enfatiza essa distinção em Ruling Passions, pp. 168-72.

12 Blackburn, 1995, pp. 704-5.

13 O jogo da chantagem e o jogo do covarde (ver nota 9) têm a mesma estrutura, mas são exemplos de casos cujos desfechos desejados podem ser opostos - pode-se desejar ser mau num caso, e desejar ser bom no outro - o que reforça a tese da inutilidade da teoria dos jogos como recomendação. 
questão deixa de ser se as ações dos agentes são ou não racionais, mas saber se eles estão preparados para enfrentar as situações que se apresentarão a eles. Tal conclusão leva Aquiles a fazer uma fogueira com os seus livros da Teoria da Escolha Racional.

Numa última tentativa de salvar o controle da razão na tomada de decisão, Aquiles se lembra do imperativo categórico, mas a tartaruga lhe mostra o comentário do próprio Kant que "a moralidade real das ações (...) permanece inteiramente escondida de nós" e que "nossas imputações podem se referir apenas ao caráter empírico", mas nunca saberemos "quanto desse caráter é atribuível ao puro efeito da liberdade e quanto à mera natureza" ${ }^{14}$.

Mas havia ainda um raciocínio cuja aceitação não tinha sido examinada pela tartaruga, um argumento do tipo meios-fins, como este:

- Se você quiser a alface, deve atravessar a estrada.

- Você quer a alface.

- Então você deve atravessar a estrada. ${ }^{15}$

A tartaruga reconhece que o argumento se parece com o modus ponens, mas não é, pois "se eu quiser um milhão, devo comprar um bilhete de loteria; eu quero um milhão, mas não aceito que devo comprar um bilhete de loteria. (...) E não vou comprar" ${ }^{16}$. Ela reconhece que, para conseguir o que quer, deve utilizar os meios disponíveis; se não fizer isso, ou não quer tanto a alface ou talvez não queira mesmo atravessar a estrada. Diz ela:

Não é um acidente (...). Se prefiro alface a morrer de fome, e reconheço que atravessar a estrada é o único meio para a alface, e mesmo assim ajo como se preferisse o par $<$ fome, ficar quieta $>$ ao par <alface, atravessar a estrada $\rangle$, então temos de achar outros motivos para explicarem minha escolha. É igualmente óbvio que tartarugas [que não] escolhem os meios necessários aos fins não alcançarão tais fins; supondo que seus fins incluem a satisfação de suas necessidades, então elas sem dúvida vão desaparecer muito depressa. ${ }^{17}$

A tartaruga acha que quem age assim, sem normas instrumentais para ajustar os meios aos fins, pode ser chamado de irracional, mas explica:

Eu chamo muita gente de irracional, (...) pessoas que ficam com raiva muito depressa ou comem muito (...). Não estou certa se vou encontrar pessoas assim, pois é difícil identificá-las e já concordamos que elas desapareceriam bem depressa. Mas, se acon-

14 Blackburn, 1995, p. 707. Citação de Kant, Critica da Razão Pura, A551/B579.

15 Ibidem, p. 708.

16 Ibidem, pp. 708-9.

17 Ibidem, p. 709. 
tecer, bem, tenho certeza que elas realmente despertariam minhas paixões — imprestáveis, animais inúteis - disse ela, franzindo a testa. ${ }^{18}$

Aquiles, perturbado com tudo o que a tartaruga lhe disse, nota que a pilha de alfaces diminuía constantemente. "Não te contei?", disse ela, "tenho uma paixão absoluta pela coisa. Na verdade, raramente resisto a isto" 19 .

\subsection{Alguns comentários}

\section{Broome: $O$ erro da tartaruga}

John Broome sugere que, para que o raciocínio meios-fins tenha a forma correta de um silogismo prático, a primeira premissa e a conclusão deveriam expressar intenções, e a segunda uma crença, como a seguir:

- Vou comer a alface.

- Para comer a alface, devo atravessar a estrada.

- Vou atravessar a estrada. ${ }^{20}$

Colocado o raciocínio na forma correta, ficaria claro que a vontade da tartaruga já estava determinada a um fim particular - comer alface - e assim o raciocínio prático instrumental entraria em cena para levar a vontade a tomar os meios necessários para chegar a tal fim.

Entretanto, parece não haver um consenso quanto ao que seria uma forma padrão de um silogismo prático. Numa outra versão, diferente da proposta por Broome, a primeira premissa conteria uma característica geral, a segunda um exemplo, e a conclusão expressaria uma intenção. Em qualquer das duas versões, o problema da motivação da ação se manteria, pois poderíamos aceitar as premissas sem necessariamente realizar a ação.

Em outro paper, Broome aponta que seria um exagero considerar, como Hume, que a "razão é a descoberta da verdade ou falsidade" ${ }^{21}$ exclusivamente, pois tanto o raciocínio teórico como o prático estão relacionados à verdade ou falsidade do conteúdo das proposições, mas têm atitudes diferentes para encarar a verdade: no teórico, aceita-se ou não algo como verdadeiro; no prático, a atitude é pretender que algo se torne verdadeiro.

Podemos dizer que também neste caso caímos de volta ao problema analisado por Blackburn, pois não há nenhuma garantia que uma intenção seja algo puramente racional nem que motive a ação.

18 Idem.

19 Ibidem, p. 710.

20 Broome, 1999, p.11.

21 Broome, 2001, p. 2. Citação de Hume, A Treatise of Human Nature, 3.1.1.[9]. 


\section{Shaw: A tartaruga e o dilema do prisioneiro}

Patrick Shaw rejeita a tese de Blackburn de que é tautológico um jogador escolher a estratégia dominante num dilema do prisioneiro, porque não se trata da "preferência entre duas ações [cooperar x não-cooperar], mas entre os quatros possíveis resultados que são gerados pela combinação das ações de dois jogadores", conforme a seguir ${ }^{22}$ :

\begin{tabular}{|c|c|c|}
\hline Preferências & $1^{o}$ jogador & $2^{o}$ jogador \\
\hline $1^{a}$ & Falcão & pomba \\
\hline $2^{a}$ & Pomba & pomba \\
\hline $3^{a}$ & Falcão & falcão \\
\hline $4^{a}$ & Pomba & falcão \\
\hline
\end{tabular}

Segundo Shaw, cada jogador tem um controle parcial sobre a posição final pois, qualquer jogada que faça, estará excluindo dois resultados. A tautologia vista por Blackburn é que um jogador com preferências-padrão entre os possíveis resultados do jogo (e que definem o dilema do prisioneiro) também tem que ter a mesma preferência entre as ações. Shaw, ao contrário, não vê inconsistência "se alguém escolher a ação dominada, apesar de preferir o resultado-padrão, (...) [porque tal jogador] pode acreditar que nem todos os resultados estejam disponíveis ou por ser um mau estrategista" ${ }^{23}$.

A primeira questão colocada por Shaw, a de que, ao fazer uma escolha, um jogador estará excluindo dois resultados, seria verdadeira para um observador neutro, mas não para o outro jogador. Este, por hipótese, sabe apenas que uma escolha foi feita, mas não sabe qual foi a opção escolhida.

A segunda questão talvez seja esclarecida pela distinção que Blackburn faz entre um jogo teórico e um jogo empírico. Seria tautológico fazer uma recomendação num jogo empírico, porque, no plano teórico, os prêmios e as regras foram fixados pela modelagem de um suposto comportamento - seria um conselho inútil para um caso que estivesse ocorrendo na prática. As razões citadas por Shaw, e que têm a ver com a diferença entre preferência e escolha, estariam entre as muitas razões que a pessoa considera no contexto de sua decisão, e que talvez não tenham sido incluídas na modelagem do jogo teórico - seja por deficiência da própria modelagem, seja porque a pessoa escolhe não querer participar daquele tipo jogo. 


\section{Conclusões}

O texto de Blackburn subscreve as teses humeanas a respeito da razão e seu papel na ação humana, distanciando-se da posição tipicamente neo-humeana, que admite a possibilidade de razoes normativas hipotéticas, que são relativas às tendências motivacionais do agente. Para $\mathbf{H u m e}^{24}$, ao contrário, a razão tem somente uma função teórica, é uma faculdade que produz relações de idéias e conexões causais, sem autoridade para motivar a ação. Um agente puramente racional, com uma mente calculadora e instrumental, seria inerte; $o$ ser humano, ao contrário, contrabalança paixões, e a paixão dominante leva à ação. Para Hume, enfim, a razão é uma mera escrava das paixões; ela nunca define ou provoca a ação diretamente.

Alguns filósofos contemporâneos, como Amartya Sen e Robert Nozick, insistem em achar uma brecha para que outros fatores, como um comportamento moral ou simbólico, sejam reconhecidos como motivadores da ação.

A crítica de Sen ao modelo adotado na teoria econômica considera que "o comportamento real dos seres humanos é afetado por considerações éticas" ${ }^{25}$, como o dever, a lealdade e a boa vontade, que podem induzir a busca por outros objetivos além do próprio bem-estar, e assim provocar desvios daquele comportamento-padrão considerado como racional.

Uma visão semelhante é apresentada por Nozick, ao notar que a introdução de axiomas de consistência na teoria da utilidade esperada, apesar de ser "um passo minúsculo além de Hume" ${ }^{26}$, abre a possibilidade de haver outros padrões normativos aos quais nossos desejos teriam que se sujeitar. Nozick não se conforma que a dimensão humana seja meramente humeana: seria diminuir nossa estatura. Uma maneira de ver que nossa racionalidade não é meramente instrumental seria pensar a respeito dos significados simbólicos das ações, independentemente do valor daquilo que produzem, pois é simbolicamente importante para nós que nem todas as nossas ações visem a satisfação de nossos desejos.

O próprio Hume justifica ${ }^{27}$ essas preocupações morais ao reconhecer em nossas preferências a influência, embora limitada e rara, de um altruísmo positivo, formado pelo nosso sentimento de amor aos amigos e pela nossa capacidade de perceber o sentimento de outros (simpatia), e que difere de um altruísmo negativo, redutível ao egoísmo. A ação humana seria resultante de

24 Ver Hampton e Miguens.

25 Sen, p. 67-8.

26 Nozick, pp. 138-40. Ver também Hampton.

27 Taylor, pp. 151-4 e 159-60, aponta, entre outras, as seguintes passagens em Hume, Treatise: 3.2.1.12, 3.2.2.5, 3.2.7.1 e 3.2.7.8. 
uma combinação de egoísmo e altruísmo positivo, mas este não é tão grande que não haja necessidade, em certos casos, de algum tipo de coerção.

Contra uma acusação de relativismo que essas idéias suscitam, Blackburn sustenta ${ }^{28}$ que no domínio da ética, que é o mesmo da escolha, as paixões individuais governam tudo, mas há um terreno comum em que os homens se entendem racionalmente, surgindo padrões de comportamento que são aprovados ou não, de maneira intersubjetiva.

Mesmo que as regras que governam nossa conduta tenham origem numa razão prática, permanece a dúvida se tais normas teriam o poder de nos motivar a agir, como mostrou a argumentação da tartaruga. Entretanto, ao adotar uma estratégia moderada para responder ao desafio humeano, uma parte da filosofia contemporânea, exemplificada por Sen e Nozick, mantém aberto um campo de pesquisa - exatamente aquele espaço em que não se sabe determinar o que vem da natureza e o que vem da liberdade (ver nota 13) — onde se examinam as interações razão-emoção e as alterações que podem surgir no contexto da decisão. Mas é difícil escapar ao desafio humeano 'radicalizado': a própria escolha do que trazer à discussão já não seria também dependente das paixões? $*$

\section{Bibliografia}

BLACKBURN, Simon. Being Good: A Short Introduction to Ethics. Oxford: Oxford University Press, 2001.

BLACKBURN, Simon. "Practical Tortoise Raising". In Mind, 104, 1995 (pp. 695711).

BLACKBURN, Simon. Ruling Passions: A Theory of Practical Reasoning. Oxford: Clarendon Press, (C1998, 2000.

BROOME, John. "Normative Practical Reasoning". In Proceedings of the Aristotelian Society, Supplementary Volume 75, 2001 (pp. 175-93). Versão utilizada: http:// users.ox.ac.uk/ sfop0060/pdf/normative\%20practical\%20reasoning.pdf.

BROOME, John. "Normative Requirements". In Ratio, 12, 1999 (pp. 398-419). Reproduzido in DANCY, Jonathan (ed.). Normativity. Blackwell, 2000 (pp. 78-99). Versão utilizada: http://users.ox.ac.uk/ sfop0060/pdf/normative\%20requirements. pdf.

CULLITY, Garrett; GAUT, Berys. "Introduction". In CULLITY, Garrett; GAUT, Berys (eds.), Ethics and Practical Reason. New York: Oxford University Press, 1998.

HAMPTON, Jean. "Practical Rationality". In: Routledge Encyclopedia of Philosophy, Version 1.0, London: Routledge, 1998.

28 Blackburn, 1998, p. 201, e Blackburn, 2001, pp. 111-2 e 129-33.

* Agradeço ao prof. Ernesto Perini dos Santos (UFMG) o incentivo à pesquisa e aos colegas do Grupo Hume / UFMG, coordenado pela profa. Lívia Guimarães, a discussão dos temas aqui apresentados. 
HUME, David. A Treatise of Human Nature. Editado por: David Fate Norton e Mary J. Norton. New York: Oxford University Press, 1739-40, 2001.

MIGUENS, Sofia. "Blackburn e Hume, razão e paixões (acerca da estrutura da motivação humana)". In Intelectu, $\mathrm{n}^{\circ}$ 7, outubro/2002. http://www.intelectu.com.

NOZICK, Robert. The Nature of Rationality. Princeton-NJ: Princeton University Press, (C)1993, 1995.

POUNDSTONE, William. Prisoner's Dilemma: John von Neumann, Game Theory and the Puzzle of the Bomb. New York: Doubleday, (1)1992, 1993.

SEN, Amartya. Sobre ética e economia. (On ethics and economics, (C1987, 1988). Tradução: Laura Teixeira Motta. São Paulo: Companhia das Letras, 1999.

SHAW, Patrick. "The Tortoise and the Prisoner's Dilemma". In Mind, 105, 1996 (pp. 475-483).

TAYLOR, Michael. The Possibility of Cooperation: Studies in Rationality and Social Change. New York: Cambridge University Press, ㄷ1987, 1997. 